\title{
Two Cases of Eating Disorders in Adolescents with Dental Braces Fitted Prior to the Onset of Anorexia Nervosa
}

\author{
Ju-Yeon Lee, Sung-Wan Kim, Jae-Min Kim ${ }^{凶}$, II-Seon Shin, and Jin-Sang Yoon \\ Department of Psychiatry, Chonnam National University Medical School, Gwangju, Republic of Korea
}

Orthodontic treatment typically occurs during early childhood and adolescence but the wearing of dental braces is often associated with sudden changes in eating patterns that prolong treatment into the teenage years. Despite these changes, psychological assessments related to eating disorders during the course of orthodontic treatment are often ignored. Based on the findings of the present case report, it is suggested that adolescent patients who wear braces and exhibit severe weight loss should be carefully monitored for psychiatric problems, including eating disorders.

Psychiatry Investig 2015;12(3):411-414

Key Words Orthodontics, Eating disorder, Adolescent, Depression, Case report.

\section{INTRODUCTION}

Orthodontic treatment aims to improve the bite or appearance of a person by the wearing of dental braces that gradually straighten and align teeth. The proportion of children treated with fixed appliances such as braces has increased steadily over the past 20 years. ${ }^{1}$ Two common reasons for seeking orthodontic treatment during childhood and adolescence are the improvement of dental aesthetics and the promotion of psychological wellness. ${ }^{2,3}$ Adolescence is a period of considerable physical, social, and psychological change and a time when many of the earliest symptoms of psychiatric disorders are first observed. However, during orthodontic treatment, the psychosocial issues of adolescent patients are often overlooked. Several studies have investigated the relationship between psychiatric disorders and dental treatment, but these reports generally focused on older age groups or pre-surgical psychological assessments. ${ }^{4}$ Thus, the present case studies describe the prolonged food restriction of two girls due to the wearing of dental braces in which pathological eating behav-

Received: July 31, 2014 Revised: November 3, 2014

Accepted: November 26, 2014 Available online: July 6, 2015

$\triangle$ Correspondence: Jae-Min Kim, MD, PhD

Department of Psychiatry, Chonnam National University Medical School, 160 Baekseo-ro, Dong-gu, Gwangju 501-746, Republic of Korea

Tel: +82-62-220-6143, Fax: +82-62-225-2351

E-mail: jmkim@chonnam.ac.kr

(a) This is an Open Access article distributed under the terms of the Creative Commons Attribution Non-Commercial License (http://creativecommons.org/licenses/by$\mathrm{nc} / 3.0$ ) which permits unrestricted non-commercial use, distribution, and reproduction in any medium, provided the original work is properly cited. iors and serious medical conditions emerged.

\section{CASE}

\section{Case 1}

A 14-year-old girl initially presented at the emergency service department in March 2014 with complaints of severe general weakness and vague abdominal pain for the last 6 days. She looked chronically ill and cachexic, weighed $32 \mathrm{~kg}$, was $155 \mathrm{~cm}$ tall, and her body mass index (BMI) was 13.33 $\mathrm{kg} / \mathrm{m}^{2}$. The patient was premenarchal at the time of admission. Her laboratory examinations revealed anemia and leukopenia with a white blood cell (WBC) count of $2,700 / \mu \mathrm{L}$, a red blood cell (RBC) count of $397 \times 10^{4} / \mu \mathrm{L}$, a hemoglobin level of $9.9 \mathrm{~g} / \mathrm{dL}$, a hematocrit level of $30.0 \%$, total protein levels of $7.1 \mathrm{~g} / \mathrm{dL}$, an albumin level of $2.8 \mathrm{~g} / \mathrm{dL}$, a sodium $(\mathrm{Na}) / \mathrm{po}-$ tassium $(\mathrm{K} ; \mathrm{Na} / \mathrm{K})$ ratio of $138 / 4.5 \mathrm{mEq} / \mathrm{L}$, and a Ca/phosphorous $(\mathrm{P}) /$ magnesium $(\mathrm{Mg} ; \mathrm{Ca} / \mathrm{P} / \mathrm{Mg})$ ratio of $8.7 / 4.2 / 2.2$ $\mathrm{mg} / \mathrm{dL}$. The patient's abdominal X-ray and computed tomography (CT) scans did not reveal significant lesions that were associated with abdominal pain and she was admitted to the pediatric ward for further evaluation regarding her physical condition.

The patient's mother agreed to further psychiatric evaluation and a non-pharmacological treatment for an eating disorder in the pediatric ward. The patient was not depressed or anxious and she did not demonstrate a disturbed body image or a fear of obesity. At that time, she met the criteria for Avoidant/Restrictive Food Intake Disorder (ARFID) as defined in 
the 5th edition of the Diagnostic and Statistical Manual of Mental Disorders (DSM-5), ${ }^{5}$ which would formerly have been diagnosed as Eating Disorder Not Otherwise Specified (EDNOS). A history revealed that the patient had been wearing braces for nearly two years to fix her misaligned teeth. Prior to wearing braces, the patient had been eating regular meals with reasonable amounts of food, and her BMI (17.1 $\mathrm{kg} / \mathrm{m}^{2}$ ) was in the normal range for her age and gender. She reported a total weight loss of $6 \mathrm{~kg}$ due to the wearing of braces, with $3 \mathrm{~kg}$ of loss coming over the previous 3 months.

At the initiation of orthodontic therapy, the patient began to cut food into smaller bites to make chewing easier and she also avoided hard foods to alleviate the pain associated with braces. Over the first few months of orthodontic treatment, the braces produced pain and discomfort while eating, and the patient developed a fear of chewing and biting. She started to skip school lunches and gradually began to eat very little at home as well. After a year, although the pain associated with the braces had diminished, the patient continued to restrict her food intake because she liked the empty feeling. As she had attributed her altered eating behavior to the discomfort caused by dental braces, her parents had believed that her restrictive eating patterns were associated with oral pain.

In the pediatric ward, the patient received psychoeducation and supportive treatment regarding eating disorders along with nutritional rehabilitation. After a period of 20 days and the resumption of caloric intake, the patient's severe leukopenia and anemia had recovered (e.g., WBC count of $4,000 / \mu \mathrm{L}$, $\mathrm{RBC}$ of $427 \times 10^{4} / \mu \mathrm{L}$, a hemoglobin level of $10.9 \mathrm{~g} / \mathrm{dL}$, and a hematocrit level of $35.6 \%$ ), and she exhibited a weight gain of $2 \mathrm{~kg}$ at discharge (Table 1). As her physical condition stabilized, she was reluctant to continue with hospital care and refused to repeat the psychiatric assessments she had completed upon admission. Thus, the patient was discharged with an appointment for healthy eating education and regular followups in the child psychiatry department.

\section{Case 2}

A 13-year-old girl was admitted to the pediatric ward in March 2014 complaining of abdominal pain secondary to acute hepatitis. A physical examination revealed general weakness, leg edema, and lanugo hair covering her back, and an electrocardiogram showed a sinus bradycardia but there were no signs of hepatic encephalopathy. Her weight was $33 \mathrm{~kg}$, she was $160 \mathrm{~cm}$ tall, and her BMI was $12.89 \mathrm{~kg} / \mathrm{m}^{2}$. The patient described a decrease in body weight from $43 \mathrm{~kg}$ to $33 \mathrm{~kg}$ over a 6-month period, and she showed a marked elevation of transaminase levels. Her laboratory examinations revealed an aspartate transaminase (AST) level of 2,820 U/L, an alanine transaminase (ALT) level of 1,950 U/L, a gamma glutamyl
Table 1. Patients' characteristics

\begin{tabular}{|c|c|c|}
\hline & Case 1 & Case 2 \\
\hline Age, years & 14 & 13 \\
\hline Period of braces, months & 23 & 7 \\
\hline \multicolumn{3}{|l|}{ Body weight, kg } \\
\hline Before braces & 38 & 43 \\
\hline Admission & 32 & 33 \\
\hline Discharge & 34 & 39 \\
\hline \multicolumn{3}{|l|}{ BMI, kg/m² } \\
\hline Before braces & 17.1 & 17.2 \\
\hline Admission & 13.33 & 12.89 \\
\hline Discharge & 14.16 & 15.23 \\
\hline $\begin{array}{l}\text { Pathognomonic laboratory } \\
\text { findings }\end{array}$ & Leukopenia & $\begin{array}{c}\text { Acute } \\
\text { hepatitis }\end{array}$ \\
\hline \multicolumn{3}{|l|}{ CDI } \\
\hline Admission & 3 & 17 \\
\hline Discharge & - & 8 \\
\hline \multicolumn{3}{|l|}{ EAT-26 } \\
\hline Admission & 5 & 45 \\
\hline Discharge & - & 24 \\
\hline Psychopharmacological treatment & None & Mirtazapine \\
\hline Length of total hospitalization, days & 20 & 36 \\
\hline
\end{tabular}

BMI: body mass index, CDI: children's depression inventory, EAT26: eating attitude test-26

transpeptidase (r-GTP) level of $120 \mathrm{U} / \mathrm{L}$, an alkaline phosphatase level of $481 \mathrm{U} / \mathrm{L}$, a total bilirubin level of $2.68 \mathrm{mg} / \mathrm{dL}$, an amylase level of $46 \mathrm{U} / \mathrm{L}$, a WBC count of $4,600 / \mu \mathrm{L}$, a total protein level of $6.9 \mathrm{~g} / \mathrm{dL}$, an albumin level of $4.8 \mathrm{~g} / \mathrm{dL}$, a RBC count of $357 \times 10^{4} / \mu \mathrm{L}$, a hemoglobin level of $11.1 \mathrm{~g} / \mathrm{dL}$, a Na/K ratio of $136 / 2.9 \mathrm{mEq} / \mathrm{L}$, and a $\mathrm{Ca} / \mathrm{P} / \mathrm{Mg}$ ratio of 9.2/2.5/2.4 $\mathrm{mg} / \mathrm{dL}$. Further evaluation ruled out drug intoxication and metabolic, autoimmune, infectious agent, and viral hepatitis etiologies. Biologically, there was a marked decrease in her transaminase levels after 7 days, which returned to normal after 12 days following adequate hydration and improved nutrition. The patient also gained approximately $2 \mathrm{~kg}$ during this period.

Subsequently, the patient was transferred to our psychiatric ward for the management of her depressed mood and eating disorder. During her visit to the psychiatric unit, the patient's symptoms were evaluated according to the DSM-5 criteria and she was diagnosed with Anorexia Nervosa (AN), restricting type. At the same time, the Children's Depression Inventory (CDI) was administered, revealing a moderate level of depression (score of 17). She had been wearing braces for nearly 7 months to treat dental malocclusion. Prior to wearing braces, the patient regularly ate an appropriate amount of food and was euthymic, but, after the first few weeks with 
braces, she experienced recurrent oral ulcers and continued pain associated with the braces. She started to eat soft noodles and semi-liquid food in small amounts to ameliorate her oral pain. The patient lost $3 \mathrm{~kg}$ of body weight over the first 3 weeks, and her friends said that her slim body looked better; she was also satisfied with her thin body image. Accordingly, she began to ingest only liquid food to avoid becoming obese even though she was already underweight and preoccupied with caloric restriction. During her 2 months of restricted eating behavior, the patient's condition deteriorated as evidenced by a loss of energy, hair loss, impaired menstrual function, and a depressed mood.

Upon admission, the patient felt that she needed to be in the hospital to recover her physical condition and reverse her weight loss. She was moderately depressed and exhibited disturbed eating attitudes and behaviors (Table 1). She was prescribed mirtazapine $(7.5 \mathrm{mg}$ ) to alleviate her depressed mood and stimulate her appetite, and she also received psychological support. Psychoeducation regarding eating disorders was provided, and her treatment plan required that her caloric intake reach at least 2,000 calories per day. The patient's weight gradually increased, from $35 \mathrm{~kg}$ to $39 \mathrm{~kg}$, over the 24 days of psychiatric admission, and her BMI was $15.23 \mathrm{~kg} / \mathrm{m},{ }^{2}$ reflecting a partial remission at discharge.

\section{DISCUSSION}

Eating disorders are common psychiatric disorders that typically begin during adolescence, which is a period important for the development of cognition and body image and when individuals are sensitive to peer influences. ${ }^{6}$ The medical complications associated with eating disorders affect virtually every organ system and persist well into the adult years. The causes of eating disorders are very complex and include both biological and psychosocial determinants. In the present cases, the patients began to display pathological eating patterns and the avoidance of food to reduce the pain associated with braces, but they did not express weight and shape concerns. Although most psychiatric disorders are often intentionally hidden in adolescence, the present cases exhibited relatively healthy eating patterns and the maintenance of weight gain until the initiation of orthodontic therapy. However, as orthodontic treatment progressed, the patients adopted pathological eating patterns that continued even after their oral pain had diminished.

Based on the present cases, it is suggested that eating problems related to orthodontic treatment may predispose adolescent patients to maladaptive coping behaviors that can trigger or maintain eating disorders. Recent reports have demonstrated that a number of patients initiated orthodontic treat- ment prior to onset of AN and that, in particular, patients with oral pain should be assessed regarding unintentional weight loss. ${ }^{7}$ Although the prior version of the Diagnostic and Statistical Manual of Mental Disorders (DSM-IV-TR) ${ }^{8}$ does not include diagnoses that adequately capture the clinical presentation of these cases, they are well categorized by the ARFID diagnostic category, which was newly included in the DSM-5. As the restrictive eating patterns of these patients continued, a diagnosis of AN, restricting type, was appropriate, especially in Case 2. Unlike the patient described in Case 2 , the patient discussed in Case 1 did not explicitly express a fear of gaining weight. However, even though she was underweight, she denied the seriousness of her weight loss during her admission interview, which may suggest a diagnosis of AN. Therefore, the observance of subtle clues that might lead to a diagnosis of an eating disorder is important.

Regarding Case 2, the patient became depressed as her dental treatment continued, and the comments of her peers regarding her thin physique probably aggravated her pathological eating patterns. The relationship between the psychological state of a patient and orthodontic treatment ${ }^{9}$ suggests the need for psychological assessment, particularly with regard to depression and anxiety, during treatment with dental appliances. ${ }^{10}$ Depression is also a common feature of $\mathrm{AN}^{11}$ and may have contributed to the weight loss and aggravation of symptoms observed in Case 2. Therefore, orthodontists and the families of patients should directly inquire about the mental state of patients and assess their compliance with healthy eating patterns with regard to appropriate referrals to mental health professionals. ${ }^{12}$

The present cases also describe the temporal relationship between severe weight loss and medical complications as both patients manifested significant end-organ dysfunction including hematologic abnormalities and hepatitis associated with starvation. End-organ impairments are prevalent in patients with severe eating disorders, ${ }^{13,14}$ and these physical conditions can be fatal if not treated adequately with nutritional rehabilitation. Fortunately, the present patients recovered and did not resist the re-feeding process or psychotherapy. In fact, psychoeducation about eating disorders plays an important role in the treatment of adolescent patients. ${ }^{15}$ In Case 1, the patient commented that if she had known the severe, and even fatal, consequences associated with severe malnutrition, she would not have restricted her food intake despite the oral pain. This suggests that primary prevention for eating disorders should be addressed not only in clinical settings but in school environments where the risk factors for the development of eating disorders are more likely to be noticed and it is easier to provide knowledge regarding healthy eating. ${ }^{16}$

Several cases of pediatric infection-triggered AN have been 
reported, raising questions about the management of children with AN suffering from a transient infection. ${ }^{17}$ This suggests that even a transient illness may be a risk factor for AN. Thus, pathological eating patterns should be evaluated in pediatric patients with physical disorders to prevent the development of AN.

In conclusion, pathological eating problems may occur in association with orthodontic treatment during adolescence. To prevent serious eating problems that are related to fatal physical conditions, a collaborative assessment between the orthodontist, the patient, the family, and a psychiatrist about the earliest signs of eating disorders is required. In addition, further investigation and longitudinal studies over a longer period of time are needed to explore the relationship between orthodontics and eating disorders.

\section{Acknowledgments}

This study was supported by a grant of the Korean Health Technology R\&D Project, Ministry of Health \& Welfare, Republic of Korea (HI12C0003).

\section{REFERENCES}

1. Chestnutt IG, Bruden DJ, Steele JG, Pitts NB, Nuttall NM, Morris AJ. The orthodontic condition of children in the United Kingdom, 2003. Brit Dent J 2006;200:609-612.

2. Cunningham SJ, Hunt NP. Quality of life and its importance in orthodontics. J Orthod 2001;28:152-158.

3. Albino JE, Cunat JJ, Fox RN, Lewis EA, Slakter MJ, Tedesco LA. Variables discriminating individuals who seek orthodontic treatment. J Dent Res 1981;60:1661-1667.

4. Kiyak H, McNeill R, West R. The emotional impact of orthognathic surgery and conventional orthodontics. Am J Orthod 1985;88:224-234.

5. American Psychiatric Association. Diagnostic and Statistical Manual of
Mental Disorders, 5th Edition. Washington, DC: American Psychiatric Press; 2013.

6. Hoek HW, van Hoeken D. Review of prevalence and incidence of eating disorders. Int J Eat Disord 2003;34:383-396.

7. O’Reilly M, Carr C, Boylan C, Anglim M, Houlihan B. Anorexia nervosa (AN) in inpatients at a children's hospital (2005-2011). Ir Med J 2014;107:53-55.

8. American Psychiatric Association. Diagnostic and Statistical Manual of Mental Disorders, 4th Edition, Text Revision. Washington DC: American Psychiatric Press; 2000.

9. Albino JE, Lawrence SD, Lopes CE, Nash LB, Tedesco LA. Cooperation of adolescents in orthodontic treatment. J Behav Med 1991;14:53-70.

10. Topcuoglu T, Yildirim O, Birlik M, Sokucu O, Semiz M. The effect of orthodontic extraoral appliances on depression and the anxiety levels of patients and parents. Niger J Clin Pract 2014;17:81-85.

11. Holtkamp K, Müller B, Heussen N, Remschmidt H, Herpertz-Dahlmann B. Depression, anxiety, and obsessionality in long-term recovered patients with adolescent-onset anorexia nervosa. Eur Child Adolesc Psychiatry 2005;14:106-110.

12. Neeley WW 2nd, Kluemper GT, Hays LR. Psychiatry in orthodontics. Part 1: Typical adolescent psychiatric disorders and their relevance to orthodontic practice. Am J Orthod Dentofacial Orthop 2006;129:176184.

13. Sabel AL, Gaudiani JL, Statland B, Mehler PS. Hematological abnormalities in severe anorexia nervosa. Ann Hematol 2013;92:605-613.

14. Rautou PE, Cazals-Hatem D, Moreau R, Francoz C, Feldmann G, Lebrec $\mathrm{D}$, et al. Acute liver cell damage in patients with anorexia nervosa: a possible role of starvation- induced hepatocyte autophagy. Gastroenterology 2008;135:840-848

15. Rosen DS, Neumark-Sztainer D. Review of options for primary prevention of eating disturbances among adolescents. J Adolesc Health 1998; 23:354-363.

16. Kreipe RE, Dukarm CP. Eating disorders in adolescents and older children. Pediatr Rev 1999;20:410-421.

17. Sokol MS. Infection-triggered anorexia nervosa in children: clinical description of four cases. J Child Adolesc Psychopharmacol 2000;10:133145. 